\title{
Woman versus Machine: Using the EMS Poly III Embedding Unit as a Novel Approach to Tissue Processing
}

\author{
Leslie Gunther-Cummins $^{1}$, Xheni Nishku ${ }^{1}$ and Frank P. Macaluso ${ }^{1}$ \\ ${ }^{1}$ Albert Einstein College of Medicine, Analytical Imaging Facility, Bronx, NY, USA.
}

Advancements in technology make new time and material saving machinery and equipment continuously available to the standard electron microscopy facility. We set out to determine if one of these aids, the EMS Poly III, available from Electron Microscopy Sciences (Hatfield, PA), is an efficient replacement of hand processing.

Hand processing of tissue samples for transmission electron microscopy is very labor intensive and time consuming. It also requires a large volume of chemistry, especially the embedding resin. The EMS Poly III attempts to eliminate some of this labor by using a built in vacuum system to provide evaporation controlled automated embedding and polymerization. The EMS Poly III replaces the resin/solvent infiltration steps that require multiple changes with increasingly concentrated resin with a single step that concentrates the resin by evaporating solvent until pure resin remains. The benefits include reduced resin use, reduced manual labor and consistent results.

To test the usefulness of this product, we chose mouse kidney and muscle tissues. The tissue was processed in parallel through the fixation and dehydration steps [1]. We then separated the samples for the resin infiltration steps. The hand processed tissue used our standard embedding protocol and the Poly III samples used Program \#3, which is designed for use with propylene oxide as the intermediate solvent.

Samples were compared via ease of sectioning and morphological appearance in the electron microscope. Both samples were sectioned on a Leica UC7 ultramicrotome (Buffalo Grove, IL) using a Diatome diamond knife (Hatfield, PA). Both tissue blocks sectioned smoothly and easily, without wrinkles and both easily formed ribbons. As shown in Figure 2, the kidneys are well preserved and infiltrated, the podocytes are well defined with an easily discernible membrane, and the slit membrane is visible in both hand and machine embedded samples. All mitochondria have obvious double membranes with clear cristae, ribosomes are clear along the endoplasmic reticulum, and the red blood cells are smooth and well embedded. The muscle tissue shows similarly preserved structure in the mitochondria and the t-tubule system is clearly visible. The filaments of the muscle fibres are easily identified and have obvious $\mathrm{Z}$ banding.

The volume of resin required to infiltrate and embed samples can increase quickly as the number of samples rises. Typically five BEEM capsules of tissue are embedded for each sample. Each vial requires at least $2 \mathrm{ml}$ of resin for each of three 100\% changes, plus the volume needed in 1:1 and 3:1 exchanges. As shown in Table 1, once the volume required for filling the BEEM caps during embedding is included, the volume of resin needed can soar. The amount of resin is $2.5 \mathrm{x}$ greater than required for EMS Poly III processing. Due to the vacuum system used by the Poly III, this volume is greatly reduced. The resins used in electron microscopy are also toxic and may cause skin irritation, so reducing exposure to the researcher may be better for their health [2]. In addition, the technicians' active time at the bench was reduced by 5 hours using the EMS Poly III. 
In conclusion, the Poly III is a technically suitable replacement for hand processing of murine kidney and muscle tissue, saving reagents and staff time for the electron microscopy facility while resulting in excellent morphological preservation.

\section{References:}

[1] O. Akchurin et al, J Am Soc Nephrol (2016) 12:3725-3737

[2] A Glauert in "Fixation, Dehydration and Embedding of Biological Specimens", ed A Glauert (NorthHolland, Amsterdam) pg. 125

\begin{tabular}{|l|l|l|l|l|l|l|}
\hline & \multicolumn{3}{|l|}{ Hand Processing } & \multicolumn{3}{l|}{ EMS Poly III Processing } \\
\cline { 2 - 7 } & $\begin{array}{l}\text { Infiltration } \\
\text { volume } \\
(\mathrm{ml})\end{array}$ & $\begin{array}{l}\text { Embedding } \\
\text { volume } \\
(\mathrm{ml})\end{array}$ & $\begin{array}{l}\text { Total } \\
\text { volume } \\
(\mathrm{ml})\end{array}$ & $\begin{array}{l}\text { Infiltration } \\
\text { volume } \\
(\mathrm{ml})\end{array}$ & $\begin{array}{l}\text { Embedding } \\
\text { volume } \\
(\mathrm{ml})\end{array}$ & $\begin{array}{l}\text { Total } \\
\text { volume } \\
(\mathrm{ml})\end{array}$ \\
\hline $\begin{array}{l}\text { 5 Samples } \\
(25 \text { BEEM Caps })\end{array}$ & 45 & 25 & 70 & 2.5 & 25 & 27.5 \\
\hline $\begin{array}{l}\text { 10 Samples } \\
\text { (50 BEEM Caps) }\end{array}$ & 90 & 50 & 140 & 5 & 50 & 55 \\
\hline
\end{tabular}

Figure 1. Volume of resin used in various quantities of samples in hand processing versus EMS Poly III processing, including volume needed for BEEM capsule.

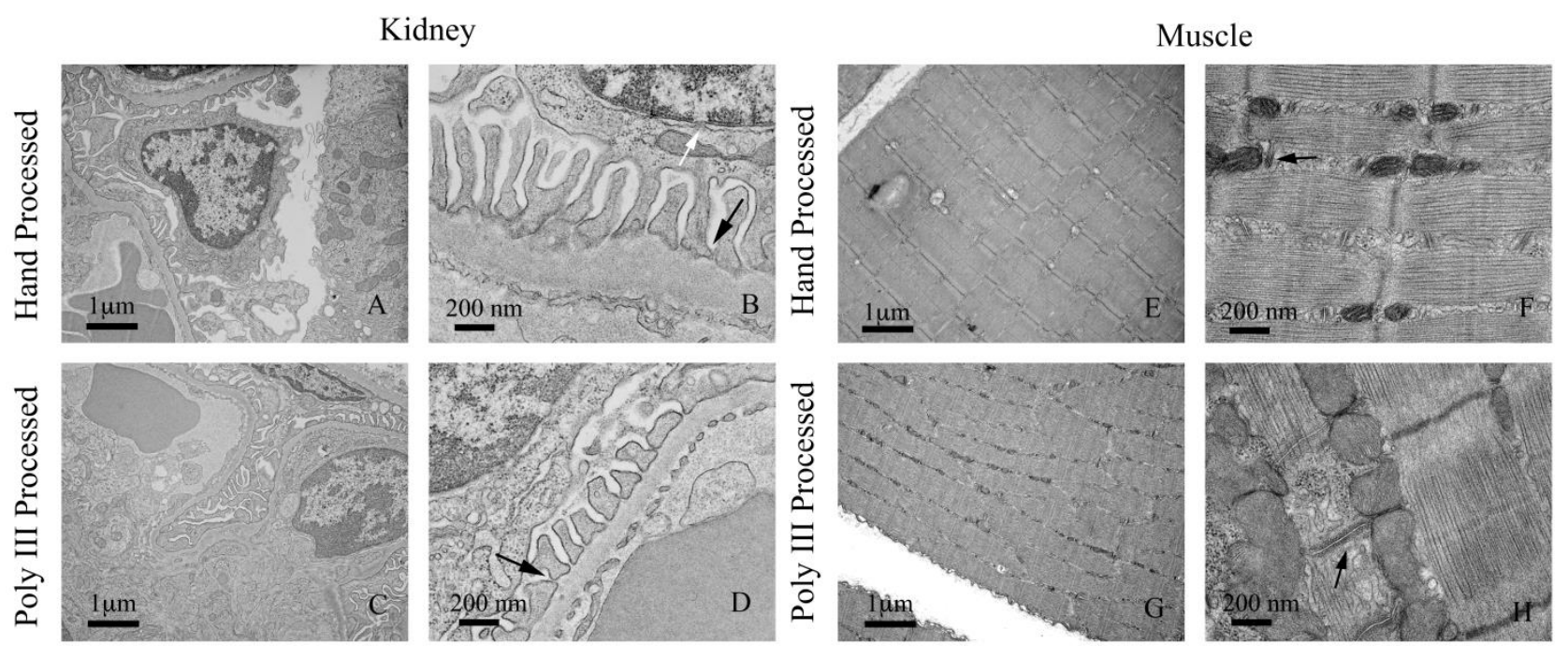

Figure 2. Representative images of mouse kidney and muscle tissue. Overall preservation is evident at low magnification and cytoplasmic details are preserved at higher magnification in both methods. The slit membrane of the glomerulus is visible (arrows) in both B) and (D), also note the nuclear pore at the white arrow. Note t-tubule system of muscle in $(\mathrm{F})$ and $(\mathrm{H})$. 